\title{
Research on Scientific Management Countermeasures for the First Semester of New Students in Military Academy
}

\author{
Jun Tang*, Jinlin Guo, Jie Jiang and Wei Gu \\ College of Systems Engineering, National University of Defense Technology, Changsha, China \\ *jun.tang@e-campus.uab.cat
}

Keywords: Military school new student, First semester, Problem status, Run-in period.

\begin{abstract}
The military academies are the cradle of modern and new military talents that cultivate the all-round development of morality, intelligence, body and labor, and play a pivotal role in the challenges of the new military revolution. However, at this stage, the management mechanism of military academies is not sound enough, the communication channels are not smooth, the working methods are simple, and the management experience is old. Especially in the management education of the first semester of new students, there are still many problems. This paper proposes management measures from the three aspects of law-based management, scientific management, and sentimental forces, so as to form a complete management method for the new students' admission difficulties, and effectively improve the management level of the students.
\end{abstract}

\section{军校新学员入学第一学期科学管理对策研究}

\author{
汤俊 ${ }^{*}$ 郭金林, 蒋杰, 顾伟 \\ 国防科技大学, 系统工程学院, 长沙, 中国 \\ *jun.tang@e-campus.uab.cat
}

关键词: 军校新学员; 第一学期; 现状问题; 磨合期

中文摘要. 部队院校是培养德、智、体、劳全面发展的现代化新军事人才的摇篮, 在面对新 军事变革的挑战中, 起着举足轻重的作用。然而, 现阶段军事院校学员的管理机制还不够健 全, 沟通渠道不畅通, 工作方法简单, 管理经验老旧等, 尤其在新学员入学第一学期的管理 教育上还存在很多问题。本文从依法治兵、科学管兵、以情带兵三个角度有针对性地提出管 理措施, 从而对新学员入学适应障碍问题形成一套完整的管理方法, 有效提升学员队管理水 平。

\section{1. 引言}

新生入学第一学期是指新生经过了为期三个月的教育引导、基础学习、军事训练等, 已 基本实现了由一名地方青年向合格军校学员的角色转变, 但由于新训时间相对较短, 部分新 学员思想不够成熟, 对军旅之路的发展方向和目标, 依然不太清晰, 加上现实环境和学习任 务的反差变化，思想也随之进入了思想波动期，难免引发各种问题[1]。

新学员的教育与管理在不同的时期有不同的特点, 即具有鲜明的时代性。传统的军校学 员教育与管理观念使学员被动的去适应、接受一切, 致使培养出来的人才往往是经验性的、 盲目性的, 其思维往往是定式的, 缺乏创新求异, 显然不适应新时代对军校学员素质的要求。 加强学员管理教育, 培养军校学员良好的心里素质、身体素质、军事素质和组织指挥能力, 
为基层培养优秀的指挥领导人才已刻不容缓。通过研究本科军事院校新学员的时代特征, 科 学合理的加以管理, 从一开始就打牢他们的各项基础, 这有助于学员本科阶段的管理, 在学 员四年的学习训练后才能成为基层部队所需要的优秀的复合型指挥人才。

\section{2. 军校新学员基本情况}

\section{1 “三个多”}

独生子女多。这是国家进行计划生育政策下的必然结果, 所占比例达到入学新学员一半 以上。

农村学员多。伴随着社会快速发展, 农村居住人口逐渐向城市方向转移, 但由于经济水 平之间的差距仍然存在, 军校学员来自农村的比例较大。

单亲家庭多。现今社会离婚率逐渐上升, 存在相当一部分新学员在单亲家庭中成长起来。

\section{2 来源不同}

经过信息统计，新学员来自五湖四海，各地区经济文化水平、饮食习惯、生活方式等都 有很大差异; 其次, 家庭环境也不同, 有的新学员家庭条件好, 有的条件差, 有的父母是农 民, 有的是工人, 还有的是干部; 此外, 除了物质条件不同, 家庭教育、父母感情及家庭环 境也不尽相同, 这导致了新学员在为人处世等各方面的差异; 最后, 他们的社会经历不一样, 所以在对事物的认知上也有差别, 朝夕相处难免会发生矛盾。

\section{3 差异明显}

新学员中有部队生和地方生, 由于他们入学前所处经历环境不同, 对部队的认识有差异, 各项素质差距也很明显。部队生入学后思想相对较稳定, 对学校的适应性也较强, 并且有一 定的军事素质、思想政治基础。而地方生适应性就相对较差, 他们需要很长一段时间来完成 从一个地方青年到军校学员的转变

\section{3. 军校新学员磨合期存在的问题}

现阶段的新学员基本都是在 2000 年左右出生, 大部分是独生子女, 不管是来自城市还是 农村, 多数学员从小就受到父辈、祖辈的细心爱护, 自身不用付出太多努力便可过着衣食无 忧的生活, 因此导致他们较强的自尊心和自信心, 自我评估往往比实际高, 同时也因从小缺 乏挫折和磨练, 导致抗压能力和心理承受能力差, 不能较快适应集体生活从而出现各种各样 的问题。

\section{1 思想上出现波动}

新学员入伍原因多样, 动机现实, 既有向往军队生活, 渴望成为一名军人, 希望为部队 建设做贡献从而实现自身价值, 也有因为就读军校后没有找工作的烦恼, 把部队当作 “避风 港”，同时还有因自身比较叛逆，父母希望把他们送到部队好好管教等。不同入伍动机的新 学员面对严格的军事训练管理, 隐私较少的集体生活, 有规律的学习训练, 容易发生这样那 样的碰撞、摩擦和矛盾。由家庭高度呵护到融入集体迈入正式学员的行列, 容易产生失落受 挫的情绪, 找不到自身存在感和价值感, 思想上难以接受。由单一的中学教育到担负各项训 练任务, 还要面对公差勤务分配、学专业、评功评奖等个人切身利益的现实问题, 容易因一 时难以适应新的生活节奏，面对种种压力往往会产生自暴自弃的思想，消极对待。

\section{2 心理上问题增多}

经过为期三个月的思想政治教育和军事训练, 绝大多数新学员已经实现了由一名地方青 年向合格军校学员的角色转变, 但由于新训时间相对较短, 部分新学员思想不够成熟, 对军 
旅之路的发展方向和目标, 依然存在迷惑, 加上现实环境和学习任务的反差变化, 导致部分 新学员因一时难以适应而引发各种问题[2], 主要表现几种: 一是军校学员在繁重的课程学习 之余, 还要进行大量的军事和体能训练, 就使新学员觉得与理想中的大学生活不符, 从而产 生懈怠和厌烦情绪; 二是在对待个人荣誉和成绩时，在付出一定的劳动而没有达到自己的期 望时, 易于出现情绪波动, 产生失落感和心理落差; 三是部分环境适应能力较差的新学员无 法适应多维、层级的内部管理关系, 经常感受处于管理末端, 受他人监督, 而产生逆反和抵 触心理; 四是因为专业技术学习任务加重, 部分新学员跟不上学习进度而对自身的智力和能 力评价过低, 感到已不如人, 导致自卑心理产生。

\section{3 训练上缺乏主动}

军事训练是考核评估的一个重要指标, 往往受到学员队高度重视, 而入学不久的新学员 军事素质往往参差不齐, 有些军事素质较差的新学员在训练中往往感到比较吃力, 身体负担 较大, 再加上在评比考核中落后, 心理压力也随之上升, 往往会对训练失去信心, 失去热情, 训练消极急工, 能偷懒就偷懒, 漏训、怕训, 训练积极性不断降低, 长此以往, 导致军事素 质越来越差。如果学员队急于求成, 不考虑新学员的具体情况, 一味进行高强度的训练, 不 注重科学施训, 往往事倍功半, 达不到预期的目标, 甚至导致训练伤病和训练事故的发生, 让下队新学员对军事训练产生畏惧情绪, 厌训、逃训, 为了逃避训练出现装病情况。

\section{4 秩序上出现混乱}

正规的秩序是进行各项学习训练的保障, 而有效的管理是实现这一目标的根本途径。学 员队对入学新学员教育、训练、管理的根本目的, 在于使其能尽快适应军校学习生活。然而 由于各种原因, 学员队管理或多或少存在一些错误的做法。特别是现阶段新学员较之前任何 一批更具有自己的主观想法与意识观念，他们对权威和强制性的命令或灌输易于产生抵触、 反感情绪, 希望得到应有的尊重, 通过民主、沟通、协调的方式解决问题, 而这一诉求在军 事院校往往很难得到满足。一些学员队领导不顾客观实际, 抛出一系列严格禁令, 处处严禁, 时时设防, 迫使新学员机械服从。新学员各方面的能力素质不同, 适应新环境的能力也不一 样, 对连队的管理或多或少会有不适应的地方, 学员队如果不能采取合理的管理方式, 新学 员违规违纪情况就会频繁发生, 例如喝酒斗殴、私自外出、夜不归宿等。

\section{4. 军校新学员磨合期管理对策}

如果军校新学员磨合期存在的问题不能及时解决, 不仅影响新学员在部队的工作生活, 还会严重影响部队的长期发展。因此, 为了使新学员能够尽快适应军校管理模式, 并能够迅 速地进入学习工作角色, 就有必要制定出一系列针对磨合期的解决策略。

\section{1 坚持依法治队}

习主席在出席十三届全国人大一次会议解放军和武警部队代表团时强调, “要加大依法 治军工作力度, 强化法治信仰和法治思维, 加快构建中国特色军事法治体系, 加快推动治军 方式根本性转变。” [3]。军无法不立, 法无威不严, 严则所向披靡, 松则溃不成军。军校新 学员是部队的新鲜血液, 必须依据条令条例和规章制度对他们进行严格管理, 确保部队战斗 力的生成。

\subsection{1 强化条令意识}

条令条例是部队共同的行为规范, 是贯彻依法治军、从严治军的方针原则, 是提升部队 正规化建设标准的根本依据, 加强新学员的条令条例学习是他们走好军营的第一步。学习条 令条例目的在于帮助新学员切实弄清应该怎么做、不应该怎么做, 什么是对的、什么是错的, 从而更好地促使新学员建立正确的行为规范。要广泛利用网络电视、报刊杂志、演讲比赛、 
文艺活动等学员喜闻乐见的形式, 将条令学习融入到学员队经常性管理工作和学员日常生活 中, 不断浓厚细致学习条令、依法使用条令的良好氛围。

\subsection{2 狠抓日常养成}

在日常管理中, 坚持教育训练规范化、一日生活合理化、各项工作有序化; 要高标准抓 管理, 坚持严格管理、严格军事训练、严格制度落实、严格执行纪律, 不断提高入学新学员 的法纪意识。坚持从日常制度抓起, 从入学新学员的点滴养成抓起, 培养人人、时时、处处 按条令办事的良好习惯, 坚决做到条令条例常态化落实, 把各项工作都纳入法制化轨道, 努 力做到队干部依法指导, 新学员依法落实。

\subsection{3 严格赏罚分明}

学员队管理要坚持有法必依, 执法必严, 用条令条例来说话, 不讲价钱, 不打折扣, 统 一标准, 新老学员不区别对待。对待任何违规违纪的行为坚持违法必究, 使下队新学员养成 敬畏纪律、崇尚纪律、遵守纪律的意识。同时, 要树立典型, 主动发现那些自我要求严格、 尽心屡职尽责、努力做出成绩的新学员, 适当给予表彰和奖励, 确实做到在奖惩上奖得让新 学员心动、惩得让新学员心痛。

\section{2 加强科学管队}

建设一流军队呼唤一流人才, 培育一流人才需要科学手段。我们必须树立适应新时代使 命要求的带兵育人思维, 积极创新思路理念、运行模式、指导方式, 为实现强军目标打下坚 实基础。

\subsection{1 做好思想教育}

做好新学员入学第一学期的思想工作是开展各项管理活动的基础, 入学之初是思想浮动 期, 必然会出现多种各样的思想问题, 动摇管理根基。做好新学员思想工作要注意: 一是要 发挥好档案作用, 多关注单亲家庭新学员, 同时也要关注家庭经济条件特别好的新学员, 还 要关注年龄较大的新学员, 有针对性地做好这些 “关键” 学员的思想工作; 二是要在入学之 初就及时开展思想教育, 最大限度地让新学员了解部队, 从而统一思想强化当兵信心, 进而 筑牢 “当好兵” 的思想基础; 三是要建立部队家庭双向定期交流制度, 要充分认清家庭是新 学员思想稳定工作中较为重要的因素之一，为新学员思想稳定工作提供了坚强保证。

\subsection{2 实施科学训练}

军事训练是提升部队战斗力的唯一方法, 而新学员厌训、怕训、逃训情况比较明显, 训 练事故时有发生。搞好新学员的军事训练要做到: 一是队干部在做训练计划时, 应充分了解 新学员的身体承受能力和心理素质情况, 结合训练的内容、强度以及新学员身心承受能力, 加强训练的针对性和科学性; 二是根据天气变化情况, 合理调整训练安排, 做到因时制宜; 三是坚持循序渐进, 因人施教, 坚持讲解要领清楚、示范动作标准, 做好训练中的安全事故 防范。

\section{2 .3 注意管理方法}

现阶段新学员有较强的自我主张和思考辨析能力, 沟通时应注意避免灌输式的宣讲教育, 可以多提问, 多倾听, 了解他们对事情的看法, 对相互间沟通和问题的解决有积极意义。改 进管理方法要牢记: 一是多包容、少批评, 当新学员较为圆满的完成了工作任务时, 应适时 给予表扬与激励, 当出现错误时, 应多包容与及时指导; 二是及时了解掌握并帮助新学员解 决实际问题和困难, 让他们感受到学员队大家庭的温暖, 从而坚定自己的选择, 加强使命感 和归属感; 三是要努力为新学员构建发展道路, 依据新学员自身特点, 为他们绘制发展蓝图, 使他们在军旅生涯中不偏离方向。 


\section{3 做到以情带队}

以情带队则是基层学员队管理好学员的关键, 而刚踏入军营的新学员在情感上更需要关 怀, 在入学新学员生活、训练和情感方面给予关心和指导, 对做好下队新学员的管理工作至 关重要。

\subsection{1关注日常生活}

学员队干部应热情主动, 积极为新学员排忧解难, 解决好他们在日常生活中遇到的各种 问题, 具体做到谈心交流实, 帮助态度实、训练劲头实, 特别是当新学员因不适应新环境而 产生思想起伏时, 作为队干部要做到多理解少怀疑, 多帮助指导少牢骚抱怨, 一视同仁, 为 他们创造温馨的良好军营环境。

\subsection{2 指导学习训练}

作为新学员军旅生涯首任老师的学员队干部, 其能力素质水平和训练管理模式对于新学 员能否快速融入军营生活起着举足轻重的作用。针对新学员可能遇到的训练困难, 要精心研 讨, 对待新学员要细心呵护, 精雕细环。在训练管理上做到公平公正、一视同仁; 在训练方 法上做到会观察总结、会思考借鉴、会启发诱导, 防止简单粗暴; 在训练教学中坚持学用结 4.3.3 培养思想感情

新学员告别各自亲朋好友步入军营, 环境生疏, 生活习惯不尽相同、方言俚语多种多样, 在军营这个大家庭中很想找到知心朋友, 队干部应及时把握新学员这一心理需求, 主动融入 他们的生活、了解他们的思想、关注他们的困难, 既是他们的领导, 又是他们的战友。

\section{5. 结束语}

随着军校编制体制的不断改革以及生源构成的日益复杂, 新学员的思想、各项素质以及 存在的问题都与以往会有很大不同, 所以针对新学员入学第一学期的管理手段也要相应改变。 首先思维模式要改变, 不能只依靠旧观念, 老思想, 更多的要考虑到这一时期新学员的特点, 从他们的价值观, 思维方式入手来想办法; 其次要践行科学发展观, 开阔视野, 多做创新, 把科学技术运用到院校管理。

\section{References}

[1] YU X. Z. Goyal, Investigation and Analysis of Mental Health Level and Personality Characteristics of New Students in a Military Academy[J], People's Military Surgeon, vo53.10, pp. 733-734, 2010.

[2] REN M, YANG H, YANG Z. B and et al, Trends and correlations of mental health status and self-efficacy before and after military training for military freshmen[J], China Journal of Health Psychology, vo20.4, pp. 606-608, 2012.

[3] Commentator, Strengthening the Work of Administering the Army According to Law--Three Discussions on Studying and Implementing Chairman Xi's Important Speech at the Plenary Meeting of the People's Liberation Army and Armed Police Force Delegation[N], China Military Network, 2018.03.15. 